\title{
Composition to Interfacial Activity Relationship Approach of Petroleum Sulfonates by Fourier Transform Ion Cyclotron
}

\section{Resonance Mass Spectrometry}

Fernando A. Rojas-Ruiz, ${ }^{\dagger \dagger}$ Mayra F. Rueda ${ }^{\dagger \dagger}$ Zarith Pachón ${ }^{\dagger}$, Álvaro Villar-García ${ }^{\dagger}$, Andrea Gomez-Escudero ${ }^{\dagger}$, and Jorge A. Orrego-Ruiz ${ }^{\dagger}$.

${ }^{\dagger}$ ECOPETROL, Instituto Colombiano del Petróleo, Piedecuesta, Santander 681018, Colombia.

${ }^{\dagger \dagger}$ Universidad Industrial de Santander, Grupo de Investigación Recobro Mejorado, Bucaramanga, Santander, Colombia

\section{SUPPORTING INFORMATION:}

\section{RPB Reactor}

RPB reactor consisted mainly of a rotor packed bed structured in stainless steel, a fixed housing, and three different inputs to introduce liquid or gas. Figure S1 shows an outline of the packed beds used in the RPB system which are unified to a turntable inside the reactor housing as it is shown in figure $\mathbf{S 2}$.

$\underline{\text { Rotor } 1}$

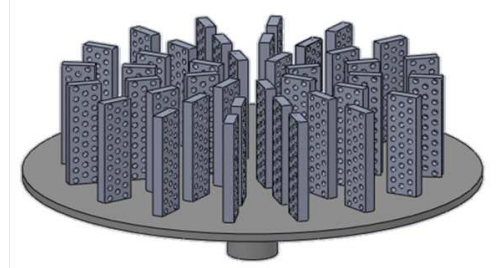

$\underline{\text { Rotor } 2}$

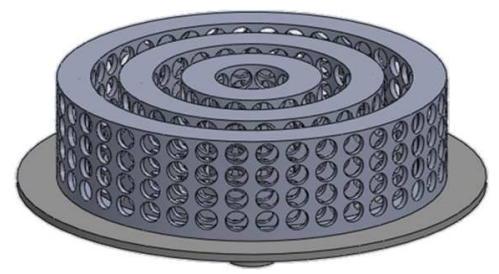

Figure S1. Scheme of the packed beds used in the RPB system. 
Rotor 1 consisted of three series of plates with $3.9 \mathrm{~cm}$ width, $12.0 \mathrm{~cm}$ long and $4.0 \mathrm{~cm}$ thick arranged concentrically and perforated with three rows of circles of diameter $0.2 \mathrm{~cm}$ and separated by $0.4 \mathrm{~cm}$. Rotor 2 had three concentric rings with outer diameters of 5.0, 9.4 and 13.8 $\mathrm{cm}$ and a thickness of $12.0 \mathrm{~cm}$, each ring had four sets of perforations of diameter $0.8 \mathrm{~cm}$. A surface area of $103 \mathrm{~cm}^{2} / \mathrm{cm}^{3}$ and porosity of 0.3 was established. Studies have reported that the division of these rings in the packing slip promotes specifically the tangential speed by enhancing the mass transfer coefficient by the gas.
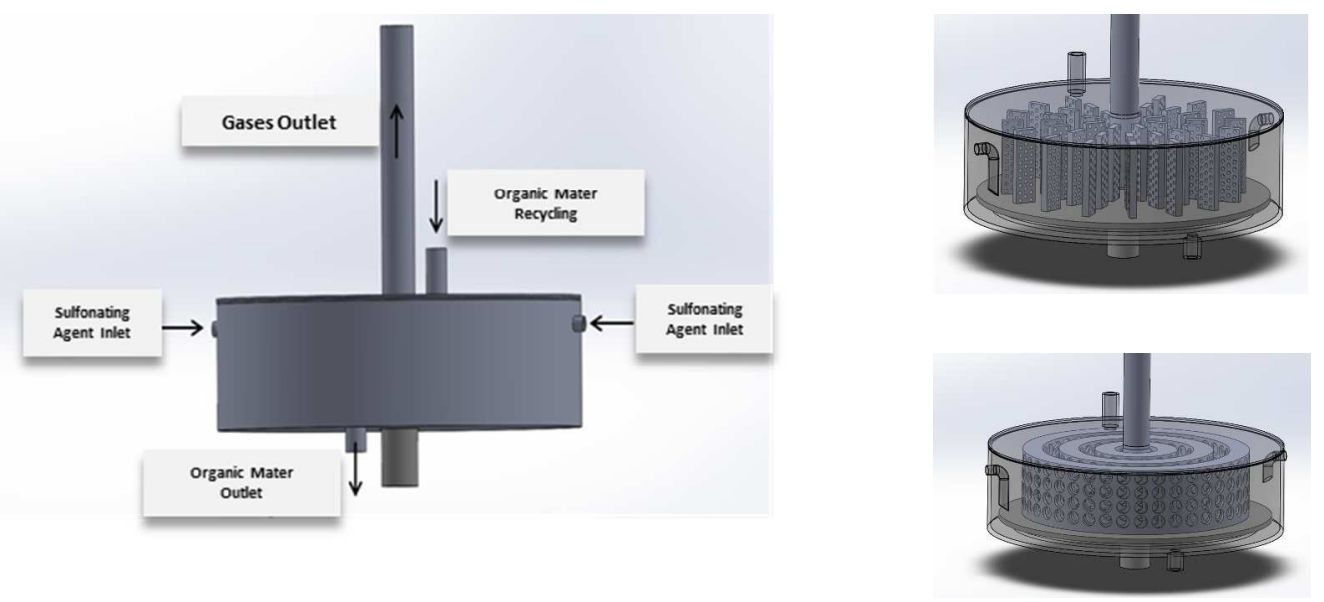

Figure S2. Packed beds unified inside the RPB reactor housing

\section{Characterization of the lipophilic-hydrophilic nature of the surfactants}

The lipophilic-hydrophilic nature of the obtained petroleum sulfonates and their preliminary assessment for potential use in chemical recovery were conducted by salinity scans measurements, where linear alkanes and crude oils were used as oil phase and $\mathrm{NaCl}$ in type I water as aqueous phase. Each scan underwent with raw crude oils I, P and T at the respective reservoir temperatures and densities of fluids (aqueous phase and oil) were adjusted by the temperature change. Figure $\mathbf{S 3}$ shows the spinning drop tensiometer employed for the Interfacial Tension (IFT) measurements and a few examples of oil drops and diameter measurements for Sigma parameter $(\sigma)$ and Optimal Salinity $\left(\mathrm{S}^{*}\right)$ determinations. 


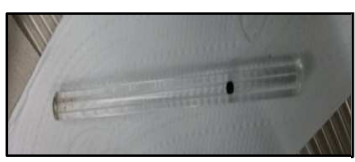

Drop of oil into the aqueous phase in the capillary_drop tensiometer.

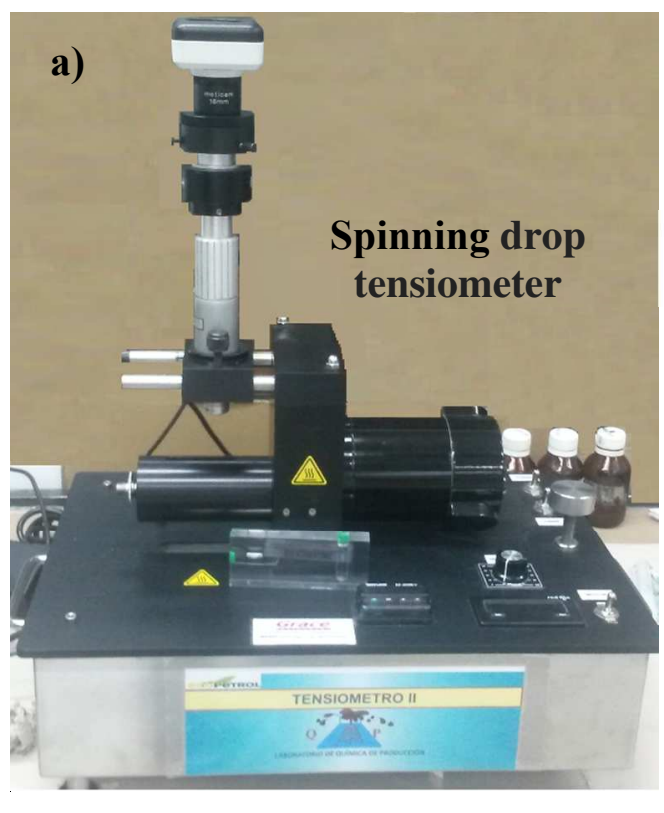

b) Drops of oil and diameter measurements
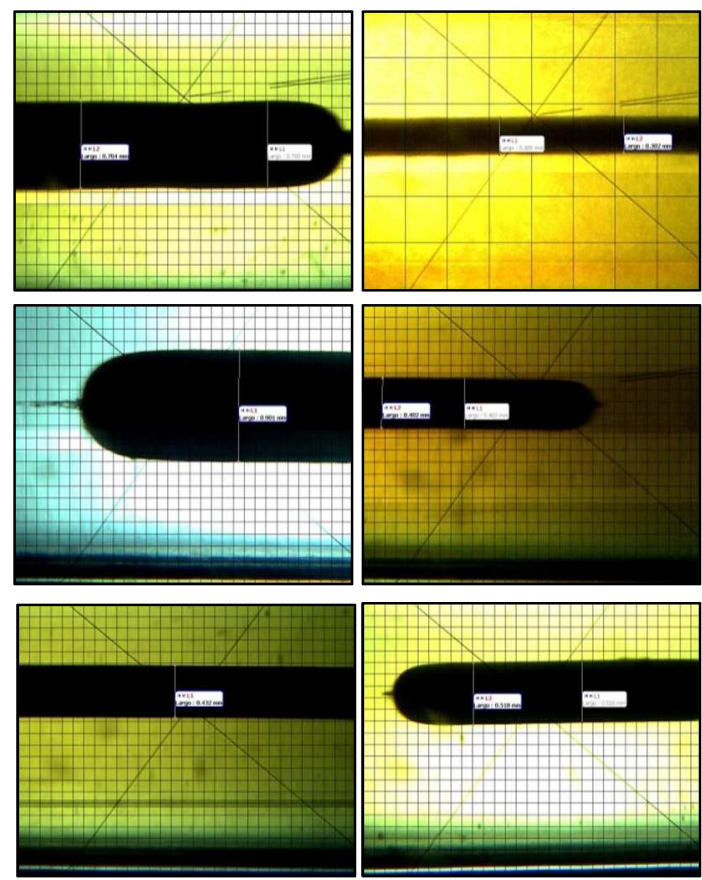

Figure S3. a) Spinning drop tensiometer employed for the IFT measurements and b) a few examples of oil drops and diameter measurements for Sigma parameter $(\sigma)$ and Optimal Salinity $\left(\mathrm{S}^{*}\right)$ determinations.

\section{3. (-) ESI FT-ICR MS Analysis}

Figure S4 shows the error distributions for the main classes detected by (-) ESI for all PS samples and Wet-Silica fractions. No bias in any plot was evident because errors were distributed around cero in all cases. 


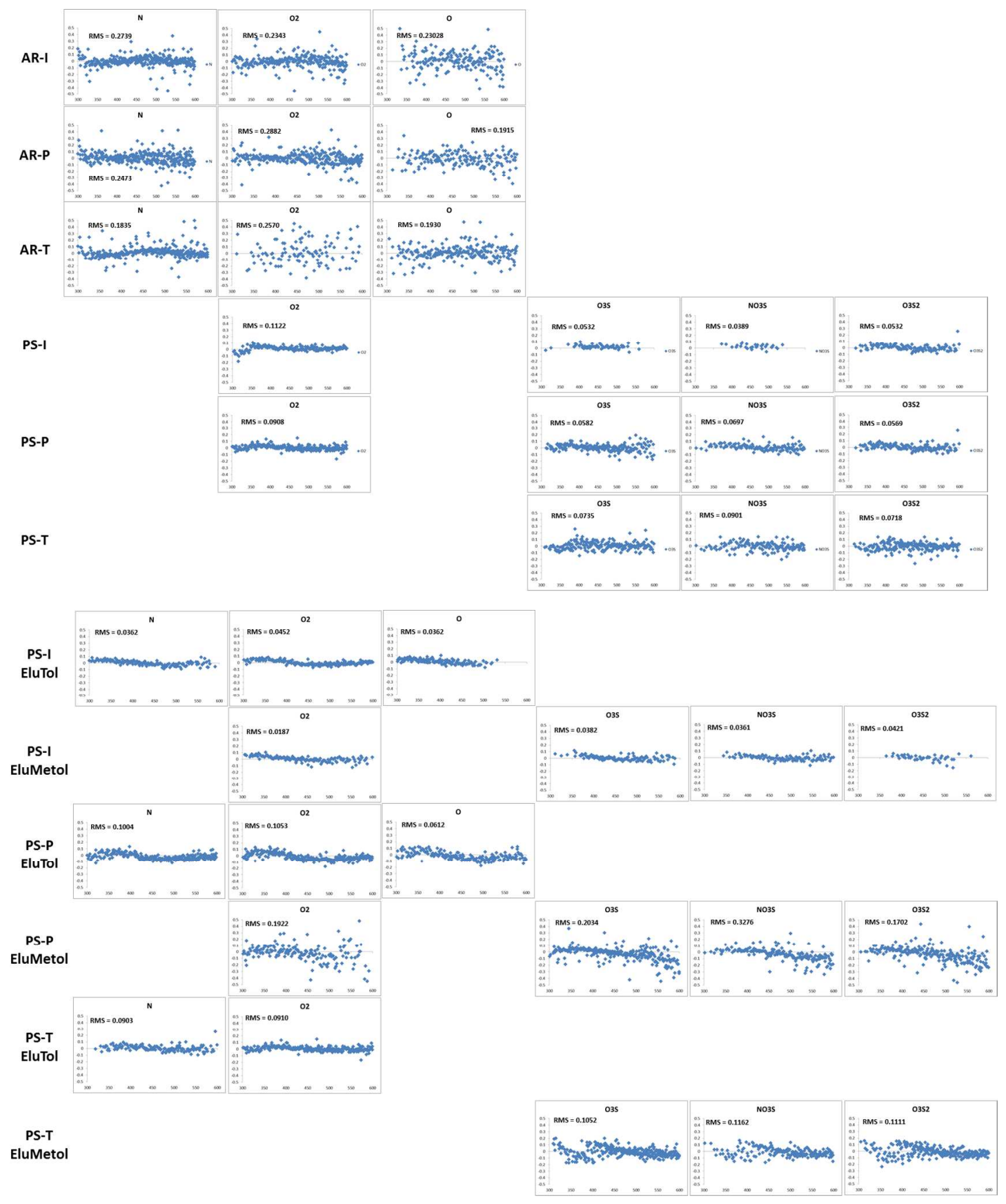

Figure S4. Distribution error graphs where the $y$ axis is the error (ppm) and the $x$ axis is the $\mathrm{m} / \mathrm{z}$ for the classes detected by (-) ESI FT-ICR MS. 